\title{
Routine immunization schedule: Update 2004
}

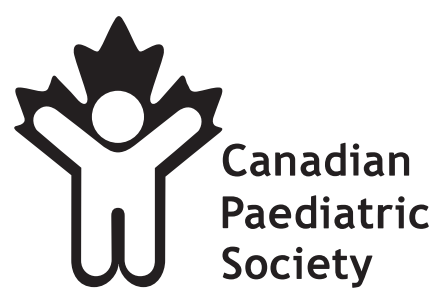

$\mathrm{T}$ he Infectious Diseases and Immunization Committee of the Canadian Paediatric Society (CPS) regularly reviews the recommendations of Health Canada's National Advisory Committee on Immunization (NACI) for the routine immunization of infants, children and adolescents. It also reviews the provincial and territorial immunization protocols. Discrepancies between what the NACI recommends and what each province and territory makes available for children and youth has been highlighted previously by members of this committee and the CPS (1-5). This note provides an update for physicians and other health care professionals on changes related to NACI recommendations (Table 1) and to the provision of vaccines by each province and territory in Canada (Table 2) (6-12).

The committee again makes a plea that all infants, children and adolescents in Canada have equal access to all NACI recommended vaccines for routine use, and that a harmonized national schedule be developed. Living in a 'have not' region should not dictate whether a child or youth has access to a 'routine' NACI recommended vaccine, nor should a move from one jurisdiction to another put a child or youth at increased risk for missing a vaccine because of regional variations in vaccine schedules.

As of fall 2003, the four 'newer' NACI recommended vaccines (varicella [9], meningococcal conjugate [10], pneumococcal conjugate [11] and adolescent pertussis [12] vaccines) were added or will be added to the schedules in some provinces and territories, albeit in many instances only for high-risk children. Table 3 summarizes these 'newer' vaccine additions by province and territory. As can be seen, none of the provinces or territories has a program for all of the 'newer' vaccines. Alberta comes closest, but does not yet fund adolescent and adult pertussis vaccines. In one territory (Yukon) and one province (Manitoba), three of the four 'newer' vaccines (varicella, meningococcal conjugate and pneumococcal conjugate vaccines) have not been added for routine use, although consideration is being given in Manitoba to add these for those at high risk of disease or complications.

Considering that the NACI recommended the varicella vaccine for routine use in infants and children in 1999 (9), it is disconcerting that by 2003 only five of the 13 provinces and territories had implemented a routine use program, particularly since the available refrigerator stable product simplifies storage and delivery issues (13). While the NACI recommendation for adolescent and adult pertussis vaccine is relatively new (September 2003 [12]), it is heartening to see that, as of November 2003, seven of the 13 provinces and territories have included this vaccine in the routine adolescent vaccination schedule.

\section{TABLE 1}

National Advisory Committee on Immunization's recommended immunization schedule for infants, children and youth

\begin{tabular}{|c|c|c|c|c|c|c|c|c|c|}
\hline Age at vaccination & DTaP & IPV & Hib & MMR & dTap or Td & HepB (3 doses) & v & $\mathrm{PC}^{*}$ & $M C^{\star \star}$ \\
\hline Birth & & & & & & infancy or preadolescence & & & \\
\hline 2 months & $x$ & $x$ & $x$ & & & & & $x$ & $x$ \\
\hline 4 months & $\mathrm{x}$ & $\mathrm{x}$ & $\mathrm{x}$ & & & & & $\mathrm{x}$ & $\mathrm{x}$ \\
\hline 6 months & $\mathrm{x}$ & $\mathrm{x}$ & $\mathrm{x}$ & & & & & $\mathrm{x}$ & $\mathrm{x}$ \\
\hline 12 months & & & & $x$ & & & $x$ & & $x$ \\
\hline 18 months & $x$ & $x$ & $x$ & $X$ or $4-6$ years & & & & $x$ & \\
\hline $4-6$ years & $x$ & $x$ & & $\mathrm{X}$ or 18 months & & & & & \\
\hline $14-16$ years & & & & & $x$ & & & & $x$ \\
\hline
\end{tabular}

${ }^{*}$ Pneumococcal conjugate vaccine (PC): doses at two months, four months and six months followed by one dose at 12 months to 15 months (11). ${ }^{* *}$ Meningococcal conjugate vaccine (MC): if started at two months, three doses; if started at four months to 11 months, two doses; if started at 12 months or later, one dose (10) (includes older children and adolescents). DTaP Diphtheria, tetanus, pertussis (acellular) vaccine, infant/child type; dTap Tetanus and diphtheria toxoid, acellular pertussis, adolescent/adult type; HepB Hepatitis B vaccine; Hib Haemophilus influenzae type b conjugate vaccine; IPV Inactivated polio vaccine; MMR Measles, mumps, rubella vaccine; $T d$ Tetanus and diphtheria toxoid, adult type; $V$ Varicella vaccine. Data from references 6,7,9-12

Department of Paediatrics, Dalhousie University and the IWK Health Centre, Halifax, Nova Scotia

Correspondence: Dr Noni MacDonald, Department of Paediatrics, IWK Health Centre, 5840 University Avenue, Halifax, Nova Scotia,

B3J 3G9. Telephone 902-470-8799, fax 902-470-7975, e-mail noni.macdonald@dal.ca 
TABLE 2

Routine immunization schedule for infants, children and youth: Provincial/territorial practices in Canada

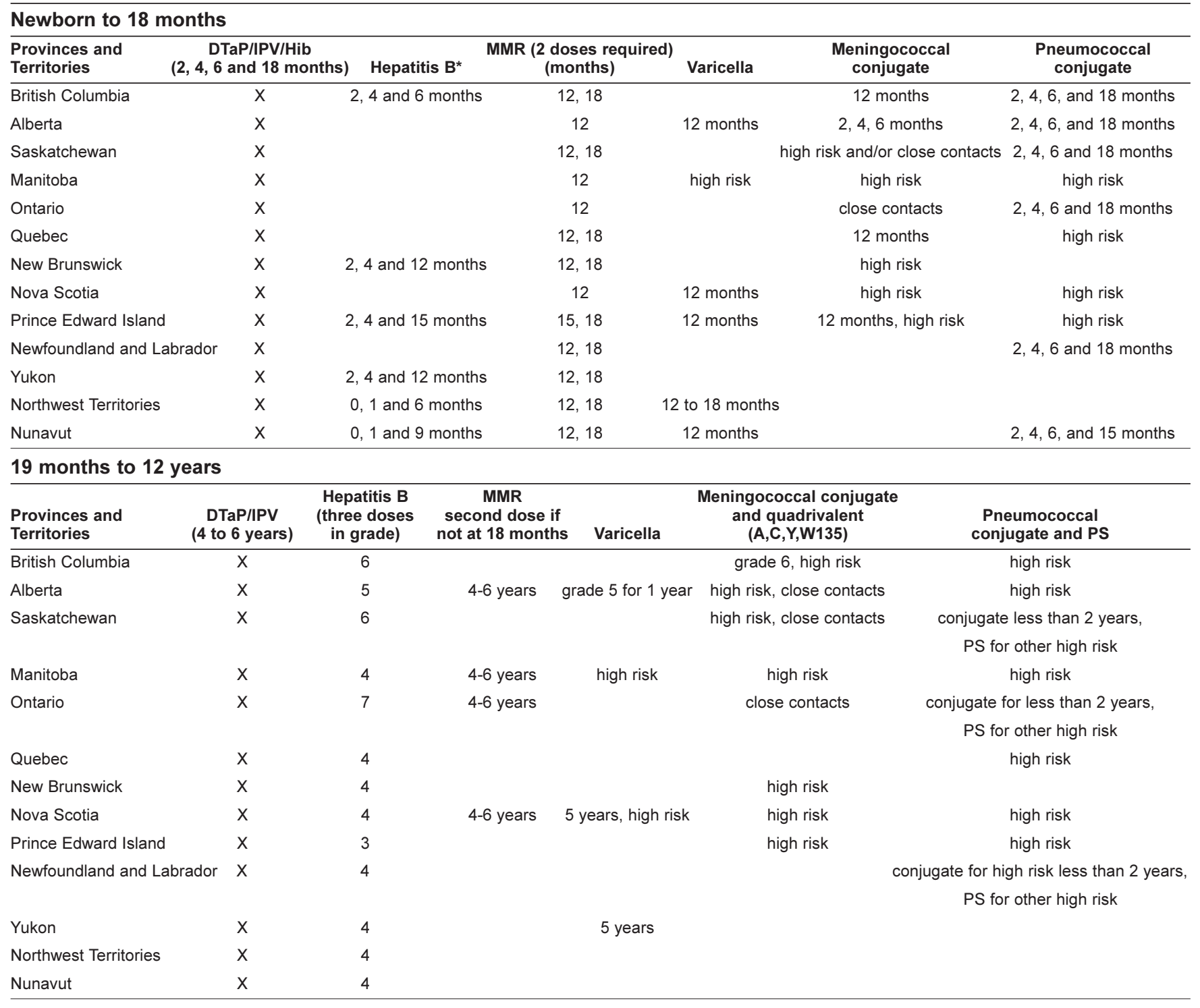

13 to 18 years

\begin{tabular}{|c|c|c|c|}
\hline $\begin{array}{l}\text { Provinces and } \\
\text { territories }\end{array}$ & Td, dTap or Td/IPV & $\begin{array}{c}\text { Meningococcal conjugate } \\
\text { and quadrivalent }(A, C, Y, W 135)\end{array}$ & $\begin{array}{c}\text { Pneumococcal } \\
\text { PS }\end{array}$ \\
\hline British Columbia & dTap & high risk: conjugate and quadrivalent & high risk $P S$ \\
\hline Alberta & $\mathrm{Td}$ & high risk: conjugate and quadrivalent & high risk PS \\
\hline Saskatchewan & dTap & $\begin{array}{l}\text { high risk: conjugate and quadrivalent; } \\
\text { close contacts: conjugate or quadrivalent }\end{array}$ & high risk PS \\
\hline Manitoba & dTap & high risk: conjugate and quadrivalent & high risk PS \\
\hline Ontario & dTap & close contacts: conjugate or quadrivalent & high risk PS \\
\hline Quebec & $\mathrm{Td}$ & high risk: quadrivalent & high risk $P S$ \\
\hline New Brunswick & $\mathrm{Td}$ & high risk: conjugate and quadrivalent & high risk PS \\
\hline Nova Scotia & $\mathrm{Td}$ & high risk: conjugate and quadrivalent & high risk PS \\
\hline Prince Edward Island & dTap & conjugate: catch up grade 9 ; high risk: conjugate and quadrivalent & high risk $P S$ \\
\hline Newfoundland and Labrador & dTap & high risk: quadrivalent & high risk $P S$ \\
\hline Yukon & $\mathrm{Td} / \mathrm{IPV}$ & high risk: quadrivalent & high risk PS \\
\hline Northwest Territories & dTap & high risk: quadrivalent & high risk $P S$ \\
\hline Nunavut & dTap & high risk: quadrivalent & high risk PS \\
\hline
\end{tabular}

${ }^{*}$ All provinces and territories recommend routine hepatitis B (Hep B) vaccination to start at birth for all infants born of Hep B infected mothers. DTaP Diphtheria, tetanus, petussis (acellular) vaccine, infant/child type; dTap Tetanus and diphtheria toxoid, acellular pertussis, adolescent/adult type; Hib Haemophilus influenzae type $b$ conjugate vaccine; IPV Inactivated polio vaccine; MMR Measles, mumps, rubella vaccine; PS Pneumococcal polysaccharide; Td Tetanus and diphtheria toxoid, adult type. Data from references 6 to 8 
TABLE 3

Availability of 'newer' National Advisory Committee on Immunization recommended vaccines by province and territory in Canada

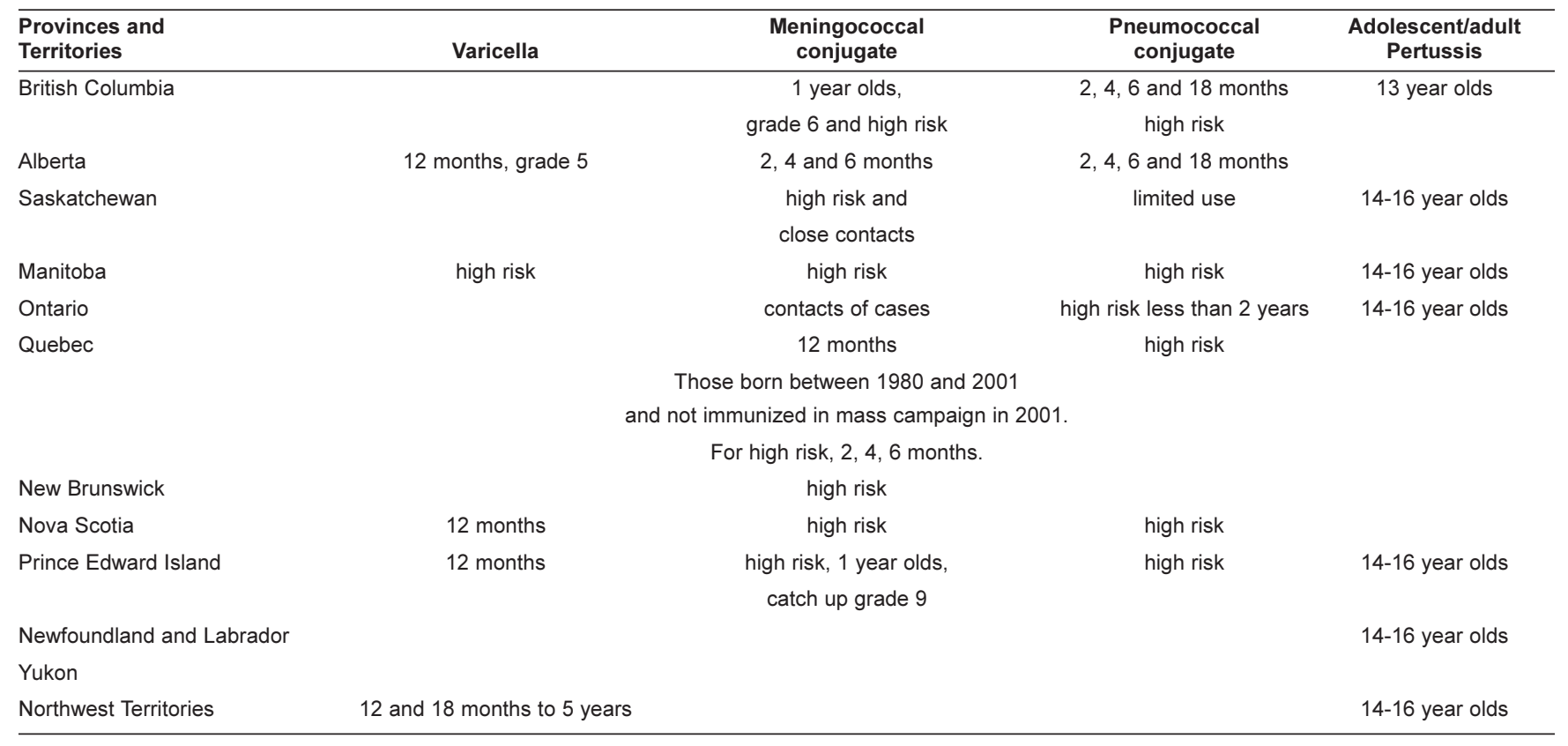

Data from references 6 and 8

Table 2 summarizes of the routine infant, child and adolescent immunization schedules in each of the provinces and territories by age group. This is a particularly important table for caregivers to consult when a child moves to a new jurisdiction because it clearly emphasizes the diversity of programs across the country. The continued marked variations across the country on the timing of the school-age hepatitis $\mathrm{B}$ vaccine and the second dose of the measles, mumps and rubella vaccine leave children and youth on the move at increased risk for missed doses. While one can recognize that in the past, different jurisdictions took different approaches based on local customs and practices, there is little scientific evidence to support one schedule over another.

A harmonized national immunization schedule would have great merit because it would reduce the risk of missed doses, further cost savings through larger purchases, and provide more uniform teaching of vaccine schedules for physicians, nurses and families. It would also simplify immunization registries and facilitate the transfer of immunization records across jurisdictions when the child or adolescent moves. The ongoing inertia in moving toward a national immunization strategy is disquieting given the professed support from all quarters for health care reforms that improve access, use resources more efficiently and lead to improved health (14).

Considering these ongoing discrepancies in access and the complexity of schedules across jurisdictions, we need to work to ensure implementation of a national immunization strategy. It must support a harmonized national schedule and guarantee access for all children and youth in Canada to all NACI recommended routine immunizations, regardless of where they live or what their families can afford to pay. Given that immunizations continue to be one of the most cost-effective preventive health measures available today, such a national strategy would clearly be in the best interest for improved health for all of our children and youth.

The recent seed money of $\$ 45$ million over five years to "assist in the pursuit of a national immunization strategy" (15) announced by the federal government in the 2003 budget is a good first step, but it is not sufficient. As noted in A Report of the National Advisory Committee on SARS and Public Health October 2003 (16), a national immunization strategy needs to be implemented more quickly and more generously. What is needed is a federal-provincial cooperative agreement that will ensure a stable pool of dedicated resources to allow the purchase, delivery and monitoring of NACI recommended vaccines for all infants, children and adolescents in Canada, regardless of the province or territory in which they live. This is what our children and youth need and deserve - not the patchwork vaccine quilt full of holes that exists today.

\section{REFERENCES}

1. MacDonald NE. Disharmony in provincial and territorial immunization schedules: A downside of recent developments. Paediatr Child Health 1997;2:171-2.

2. Scheifele DW. New vaccines and the rising costs of caring. Paediatr Child Health 2000;5:371-2.

3. Embree J. Assessing immunization programs. Paediatr Child Health 2002;7:613-4.

4. Lynk A. A call to arms (and legs): Implement the National Immunization Strategy. Paediatr Child Health 2002;7:615-6.

5. MacDonald NE, Embree J. Access to vaccines: A call to action. Paediatr Child Health 2003;8:11-2. 
6. Health Canada, National Advisory Committee on Immunization. Canadian Immunization Guide, 6th edn. Ottawa: Health Canada, 2002.

7. Health Canada, Population and Public Health Branch, Division of Immunization and Respiratory Diseases. Immunization Schedule. <www.hc-sc.gc.ca/pphb-dgspsp/dird-dimr/is-cv/index.html> (Version current at December 17, 2003)

8. Sampson H. An update in reference to the newer vaccines to the Canadian routine immunization schedule. Impact News 2003;12:3.

9. Health Canada, National Advisory Committee on Immunization. Statement on recommended use of varicella vaccine. CCDR 1999;25:1-16.

10. Health Canada, National Advisory Committee on Immunization. Statement on recommended use of meningococcal vaccines. CCDR $2001 ; 27: 2-36$
11. Health Canada, National Advisory Committee on Immunization. Statement on recommended use of pneumococcal conjugate vaccine. CCDR 2002;28:1-32.

12. Health Canada, National Advisory Committee on Immunization. Prevention of pertussis in adolescents and adults. CCDR 2003;29:1-5.

13. Health Canada, National Advisory Committee on Immunization. Update statement on varicella vaccine. CCDR 2002;28:1-8.

14. Romanow RJ. Building on Values - The Future of Health Care in Canada. Commission on the Health Care in Canada - Final Report. November 2002. <www.hc-sc.gc.ca/english/pdf/romanow/pdfs/ HCC_Final_Report.pdf> (Version current at December 17, 2003).

15. National Immunization Strategy. In: Budget 2003. Investing in Canada's Health Care System. Ottawa: Department of Finance, 2003:15.

16. Health Canada. Report of the National Advisory Committee on SARS and Public Health. Ottawa: Health Canada, 2003.

CANADIAN PAEDIATRIC SOCIETY, INFECTIOUS DISEASES AND IMMUNIZATION COMMITTEE (2002-2003)

Committee Members: Drs Upton Allen, The Hospital for Sick Children, Toronto, Ontario; H Dele Davies, East Lansing, Michigan (USA); Simon Richard Dobson, BC's Children Hospital, Vancouver, British Columbia; Joanne Embree, The University of Manitoba, Winnipeg, Manitoba (Chair); Joanne Langley, IWK Health Centre, Halifax, Nova Scotia; Dorothy Moore, Montreal Children's Hospital, Montreal, Quebec; Gary Pekeles, The Montreal Children's Hospital, Montreal, Quebec (Board Representative)

Consultants: Dr Gilles Delage, Héma Québec, Saint-Laurent, Quebec; Noni MacDonald, Dalhousie University, Halifax, Nova Scotia

Liaisons: Drs Scott Halperin, IWK Health Centre, Halifax, Nova Scotia (IMPACT); Susan King, The Hospital for Sick Children, Toronto, Ontario (Canadian Paediatrics AIDS Research Group); Larry Pickering, Centre for Disease Control and Prevention, Atlanta, Georgia (American Academy of Pediatrics)

Principal author: Dr Noni E Macdonald, Canadian Paediatric Society, Dalhousie University

The recommendations in this statement do not indicate an exclusive course of treatment or procedure to be followed. Variations, taking into account individual circumstances, may be appropriate. This article also appears in Paediatr Child Health 2003;9(1):17-20. 


\section{ERRATUM}

Canadian Paediatric Society, Infectious Diseases and Immunization Committee. Routine immunization schedule: Update 2004. Can J Inf Dis 2004;15(1):17-20.

The Canadian Paediatric Society (CPS) would like to apologize for any errors or omissions found in the January/February 2004 Paediatric Infectious Disease Note entitled "Routine immunization schedule: Update 2004." The editors have found that the charts did not accurately report all provincial vaccination programs. In addition, several provinces have added vaccine programs to their respective routine immunization schedules since January. Therefore, the charts have been republished on the CPS Web site at <http://www.cps.ca/http://www.cps.ca/english/statements/ID/PIDNoteImmunization.htm> and will be updated regularly with new data as it becomes available.

We apologize for any inconvenience this may have caused. 


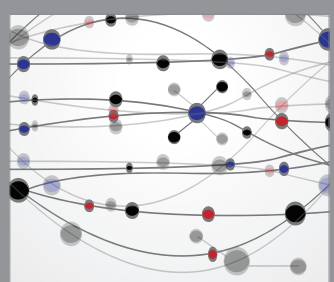

The Scientific World Journal
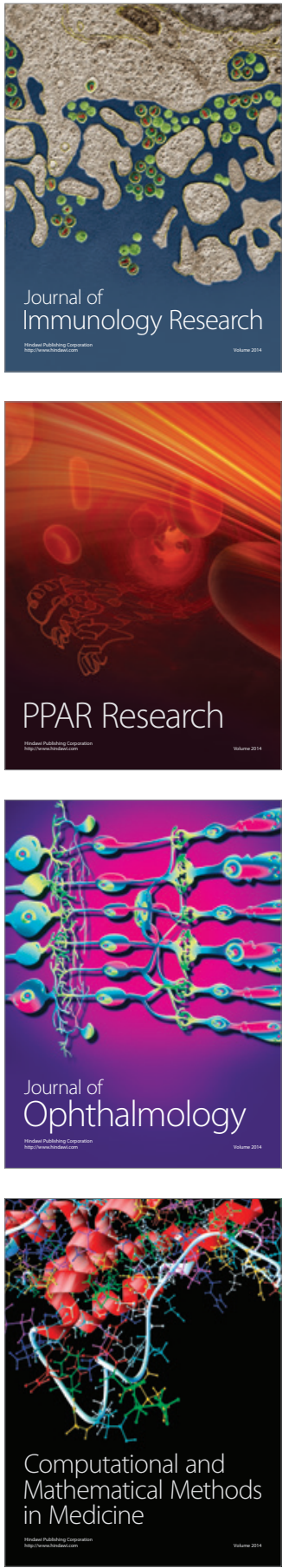

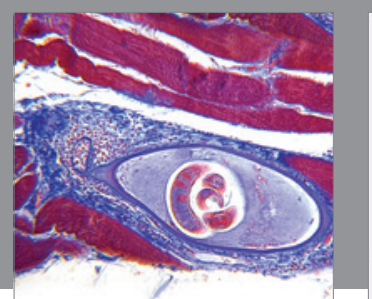

Gastroenterology Research and Practice

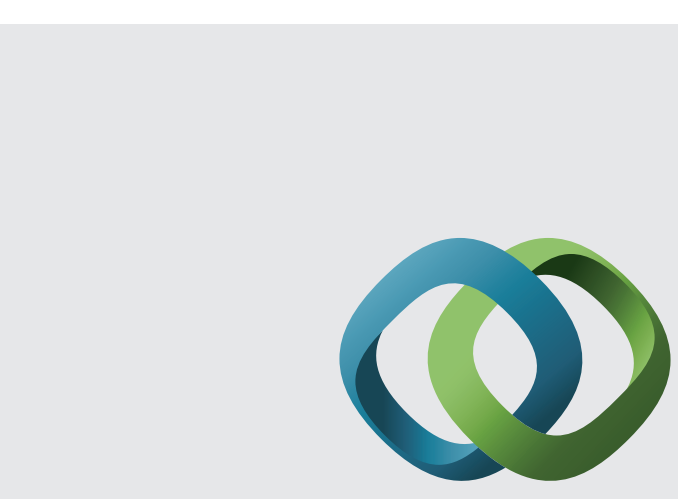

\section{Hindawi}

Submit your manuscripts at

http://www.hindawi.com
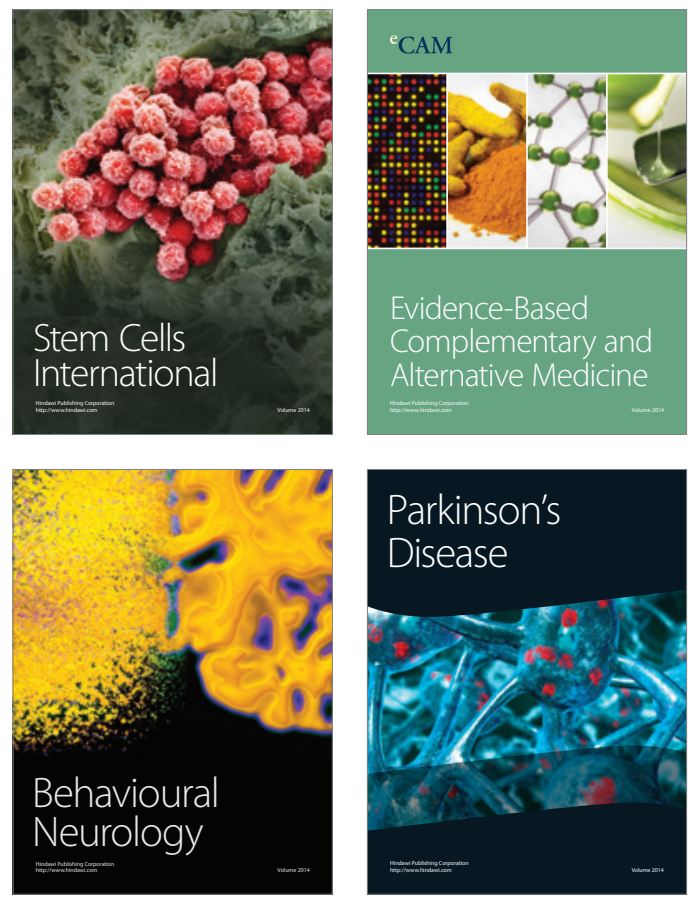
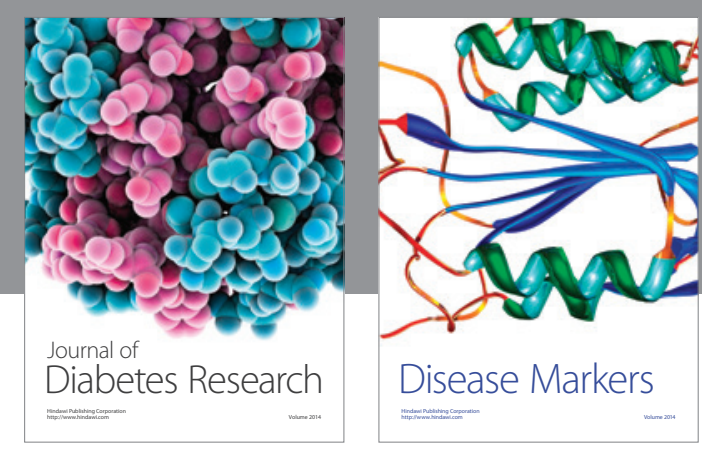

Disease Markers
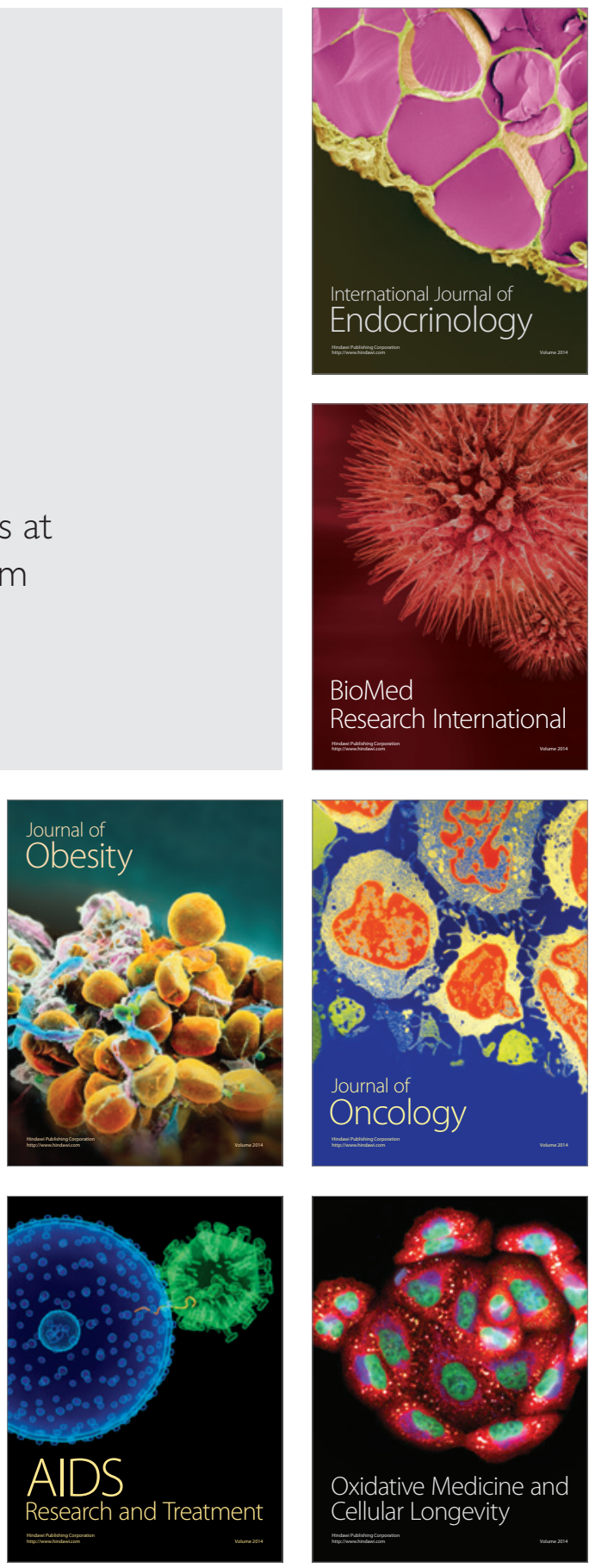